\title{
UNA POSIBLE OBRA DE PEDRO ROLDÁN, EN LA CLAUSURA DEL CONVENTO DE SANTA CLARA DE ZAFRA
}

\author{
A PROVABLE PIECE OF PEDRO ROLDÁN, IN \\ THE CLOISTER OF THE SANTA CLARA \\ CONVENT IN ZAFRA
}

\author{
Carlos Maura Alarcón \\ Grupo de Investigación HUM213: Centro de Investigación del \\ Patrimonio Artístico Andaluz. España \\ ORCID: 0000-0001-6373-2821 \\ carlos13-5-1995@hotmail.com
}

En la clausura del convento de Santa Clara de Zafra se encuentra una imagen de San Francisco de Asís que podemos incluir en el catálogo de atribuciones del escultor Pedro Roldán, hipótesis que viene refrendada por un análisis visual de la obra, así como por la documentación contextual que se conoce.

Palabras clave: San Francisco; Pedro Roldán; convento de Santa Clara; Zafra.

In the cloister of the Santa Clara convent in Zafra there is an image of Saint Francis of Assisi that we can include in the catalogue of atributions of the sculptor Pedro Roldán, thesis that is based in an visual analysis of the piece and in the contextual and historical documentation known.

Key words: Saint Francis; Pedro Roldán; Santa Clara convent; Zafra.

En el refectorio del convento de Santa Clara de Zafra nos encontramos con una imagen de San Francisco que ha pasado por diferentes ubicaciones dentro del cenobio. La pieza, de aproximadamente 1'30 m. de altura, tiene realizadas en madera tanto la cabeza como las manos - muy dañadas estas-, pies, y la parte visible del costado mientras que el hábito está resuelto con telas encoladas, posiblemente colocado durante el siglo XIX en sustitución de un primer cuerpo, quizás de candelero para vestir. Además, este añadido está creando problemas en la conservación de la imagen, ya que se está levantando por los extremos inferiores, 
dejando ver en su interior una amalgama de elementos de madera que, pensamos, se colocaron durante la intervención para darle mayor sujeción a las telas. Aunque no sabemos el alcance total de esta modificación que sufrió la obra, parece que la iconografía del santo no varió, y que en origen fue concebido igualmente para sostener un crucifijo en su mano izquierda, mientras muestra la llaga de la mano contraria. Igualmente, una abertura del hábito muestra la herida del costado, bajo la cual se deja ver el cilicio, representado con un entrelazado metálico, que a simple vista parece corresponder igualmente a la obra original. En cuanto a los ojos, se hace perceptible el uso de material vítreo, quedando en duda si serían así originalmente o si responden a una modificación posterior. Por lo tanto, estaríamos hablando de una obra, a falta de un estudio en profundidad, que conserva originales las partes en madera, así como su policromía y, presumiblemente, los ojos vítreos, mientras que el hábito es fruto de una intervención posterior, desconociendo si debajo del mismo se conservan más partes de la obra original. Por sus facciones, esta obra nos parece atribuible al escultor Pedro Roldán, a cuya producción nos recuerda el gesto y la resolución de sus partes, como el cabello y barba, a base de golpes facetados, así como el entrecejo fruncido y la boca entreabierta en actitud de exhalación.

Actualmente, este San Francisco se halla sobre una ménsula en el refectorio del convento, aunque su ubicación primera no fue ahí. De hecho, antiguas fotografías nos lo muestran en el retablo mayor de la iglesia, haciendo pareja con una imagen de Santa Clara que sigue allí ubicada. Esta colocación, formando parte del retablo, es la más antigua que de él conocemos, y nos da a pensar que pudo efectivamente haberse concebido para ese mismo sitio. El retablo mayor es una obra que se tiene bien documentada, encargada en 1670 a Alonso Rodríguez Lucas, un arquitecto de retablos extremeño que fue aprendiz en el taller de Blas Escobar $^{1}$, quien, como se sabe, fue asiduo compañero de trabajo de Pedro Roldán en varios retablos, empezando por el de Santa Ana de Montilla. Precisamente, esta relación entre los retablistas Rodríguez Lucas y Escobar nos permite plantear esta hipótesis de la autoría roldanesca, ya que el segundo vivió en Zafra durante algunos años de su vida, y la mayoría de las veces que un escultor sevillano trabaja en este entorno suele ser a través de él. Véase, por ejemplo, el retablo mayor de la iglesia parroquial de la misma población, donde Escobar realizó la arquitectura, y la escultura fue encargada a José de Arce, Alonso Martínez y a Luisa Roldán, según atribución de Alfonso Pleguezuelo que también compartimos ${ }^{2}$. Otro caso cercano puede ser el del retablo de Cristo crucificado de Almendral, población vecina de Zafra, cuyo retablo fue realizado por Blas Escobar y, en él, Pedro Roldán muy posiblemente realizara el Dios Padre del ático del mismo -según le

${ }^{1}$ Hernández Nieves, 2004: 219-223, quien tomó como referencia los datos publicados con anterioridad en Solís Rodríguez/Tejada Vizuete, 1986: 708.

2 Rubio Masa, 2001: 190-204. Pleguezuelo Hernández, 2016: 171-177. 
fue atribuido hace pocos años ${ }^{3}-$, o, por citar un último ejemplo, el de la capilla del Sagrario de la Catedral de Badajoz, encargado a él mismo y en el que trabajó como escultor Alonso Martínez haciendo las esculturas de San Pedro, San Pablo y la Inmaculada Concepción ${ }^{4}$.

Estas vinculaciones, y otras muchas que se podrían exponer del mismo entorno, explicarían sin duda la llegada de los artistas sevillanos al entorno bajoextremeño a través de Escobar, que serviría de contacto entre sus colegas de profesión o sus comitentes y sus paisanos sevillanos. Por ejemplo, en nuestro retablo de la iglesia zafrense de Santa Clara, también tiene documentados los trabajos de dorado el sevillano Diego Díaz, quien lo realizó en 1672, año en que se concluyó su hechura ${ }^{5}$, llegando así a pensar que su autor, Alonso Rodríguez Lucas, siguiera la tónica de su maestro de llamar para sus trabajos a artistas del ámbito sevillano. Pero más difícil se antoja hacer un seguimiento de las esculturas del retablo, pues la sustitución de imágenes que se observa en él hace necesario una investigación más profunda que aborde los porqués y esclarezca qué sucedió con las tallas y por qué motivo se cambiaron. Aun con todo, esta documentación nos permite advertir una posible vía por la que Pedro Roldán pudiera haber llegado a realizar las esculturas de las calles laterales, y que este San Francisco que aquí presentamos fuera el que originalmente se concibió para aquel lugar, entre 1670 y 1672.

Por último, queremos concluir estas escuetas páginas con una reflexión sobre la estética roldanesca. Cuando en su momento observamos por primera vez la imagen, pensamos que esta pudiera ser obra más de Luisa Roldán que de su padre, pues el gesto del rostro nos recordaba a otras creaciones de la artista, como la efigie del mismo santo que se encuentra en el convento Regina Coeli de Sanlúcar de Barrameda ${ }^{6}$. Sin embargo, un análisis más detenido sobre la obra nos hizo echar en falta algunos rasgos propios de sus creaciones, como la carnosidad de los labios o unas facciones menos angulosas, y es por lo que acabamos pensando que fuera obra de Pedro, pese a que el resto de obras que él produjo de similar iconografía no tienen mayor relación con esta. Véase al respecto el San Francisco que el maestro talló para Montilla en 1654, obra de un Roldán todavía muy apegado al estilo de Arce o el del retablo mayor del convento de Santa María de Jesús de Sevilla, contratado en 1690 y que muestra una estética personal mucho más asentada, pero alejada aun así de la obra que aquí presentamos. Sin embargo, en el período 1665-1675, al que Roda Peña ha denominado la "década prodigiosa" de la producción de Pedro Roldán ${ }^{7}$, y en el que enmarcamos este San Francisco que

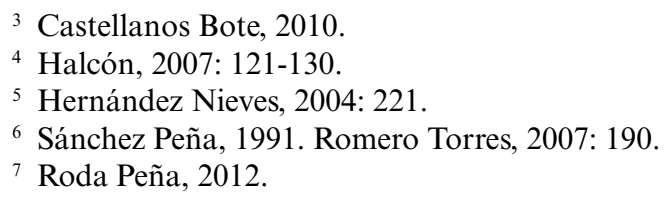


aquí nos ocupa, encontramos otras obras que nos recuerdan efectivamente a él, como algunos de los tipos masculinos introducidos en el conjunto del Entierro de Cristo de la Santa Caridad, especialmente el San Juan. En esta etapa del artista observamos la aparición de rasgos personales que toman cierta distancia respecto a sus primeras obras, pero con una variedad de registros muy amplia, precisamente también cuando la carrera de su hija Luisa está empezando a fraguarse. Las lógicas similitudes entre las creaciones de padre e hija durante estos años dificultan muchas veces el diferenciar mediante un mero análisis visual cuándo es una obra de madurez del padre o cuándo una de juventud de la hija, tal y como podría suceder con nuestra talla y con otras del mismo momento, dado que por estos años Luisa está comenzando a aprender el oficio en el taller paterno. Sin embargo, la comparación con otras posibles obras de juventud en las que participaría Luisa Roldán, como pudieran ser los ladrones del misterio de la Exaltación de Sevilla, contratados con Luis Antonio de los Arcos y Cristóbal de Guadix hacia $1678^{8}$, nos hace pensar que la resolución de esta obra habría sido diferente de realizarla la escultora, y que, por el contrario, se pueden apreciar rasgos que marcan un estilo bien asentado del maestro.

Por ello, de confirmarse esta atribución a su padre, podríamos plantear que cuando Luisa Roldán realizó el San Francisco de Sanlúcar de Barrameda, en torno a 1684 , tenía muy presente este tipo concreto que habría creado su padre para el convento zafrense, el cual reprodujo pero adaptándolo a su estilo y forma, antes de que tomara como referentes y modelos visuales a otros artistas y su obra avanzara por derroteros diferentes a los del maestro. En definitiva, y por cuanto concierne a la obra de Pedro, veríamos con esta pieza incorporado un nuevo registro a su catálogo, en el que destaca, si son originales, el uso de ojos de cristal en una fecha temprana como 1670, y consolidaría, además, la presencia de obras del artista en los terrenos del ducado de Feria.

Fecha de recepción: 27 de julio de 2020.

Fecha de aceptación: 2 de mayo de 2021.

${ }^{8}$ Roda Peña, 2007, p. 95. 


\section{BIBLIOGRAFÍA}

Castellanos Bote, Pedro (2010): http://www.lahornacina.com/articulosbadajoz2. htm (17/07/2020).

Halcón, Fátima (2007): "El escultor Alfonso Martínez y su obra en la Catedral de Badajoz". En: Laboratorio de arte, 20, pp. 121-130.

Hernández Nieves, Román (2004): Retablistica de la Baja Extremadura. Siglos XVI-XVIII. Badajoz: Diputación de Badajoz.

Pleguezuelo Hernández, Alfonso (2016): "Entre el decoro y la licencia. Nuevas obras atribuibles a Luisa Roldán en Zafra (Badajoz)". En: Laboratorio de arte, 28, pp. 171-177.

Roda Peña, José (2007): "Los encargos escultóricos de las instituciones sevillanas durante el reinado de Carlos II". En: Torrejón Díaz, Antonio / Romero Torres, José Luis (coord.): Roldana. Sevilla: Consejería de Cultura, pp. 79-103. (2012): Pedro Roldán, escultor (1624-1699). Madrid: ArcoLibros.

Romero Torres, José Luis (2007): "Luisa Roldán. San Francisco de Asís, c. 16841688”. En: Torrejón Díaz, Antonio / Romero Torres, José Luis (coord.): Roldana. Sevilla: Consejería de Cultura, pp. 190-191.

Rubio Masa, Juan (2001): El mecenazgo artístico de la casa ducal de Feria. Mérida: Editora regional de Extremadura

Sánchez Peña, José Miguel (1991): "Una obra de la Roldana en Sanlúcar de Barrameda”. En: El periódico de la bahía, 26 de mayo de 1991.

Solís Rodríguez, Carmelo/Tejada Vizuete, Francisco (1986): "Escultura y pintura del siglo XVII". En: Historia de la Baja Extremadura. Badajoz: Real Academia de Extremadura de las Artes y las Ciencias, vol. II, 681-715 


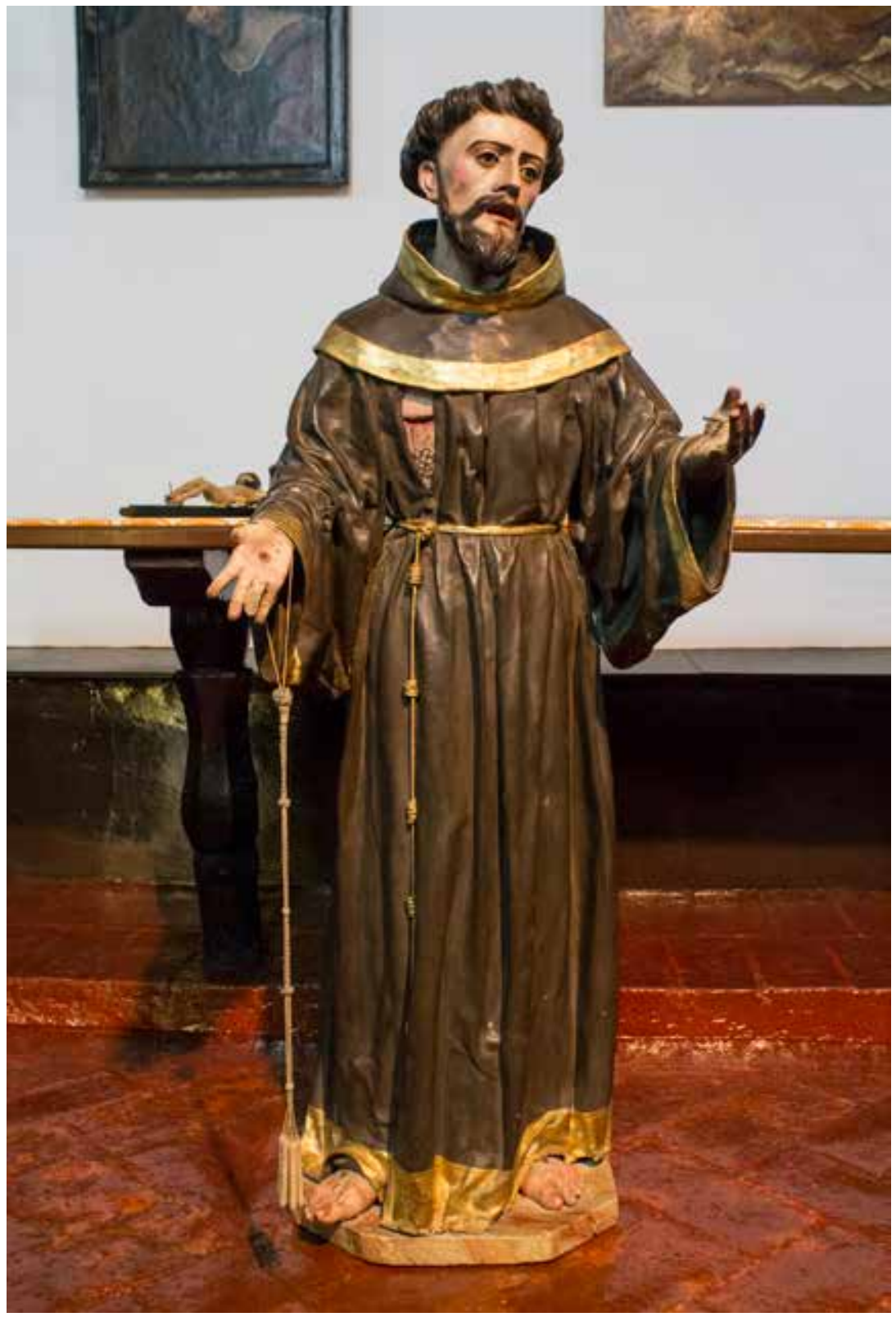

Figura 1. Pedro Roldán (atrib.): San Francisco, 1670-1672, convento de Santa Clara (Zafra). Fotografía del autor. 
Figura 2. Pedro Roldán (atrib.): San Francisco, 1670-1672, convento de Santa Clara (Zafra). Fotografía del autor.

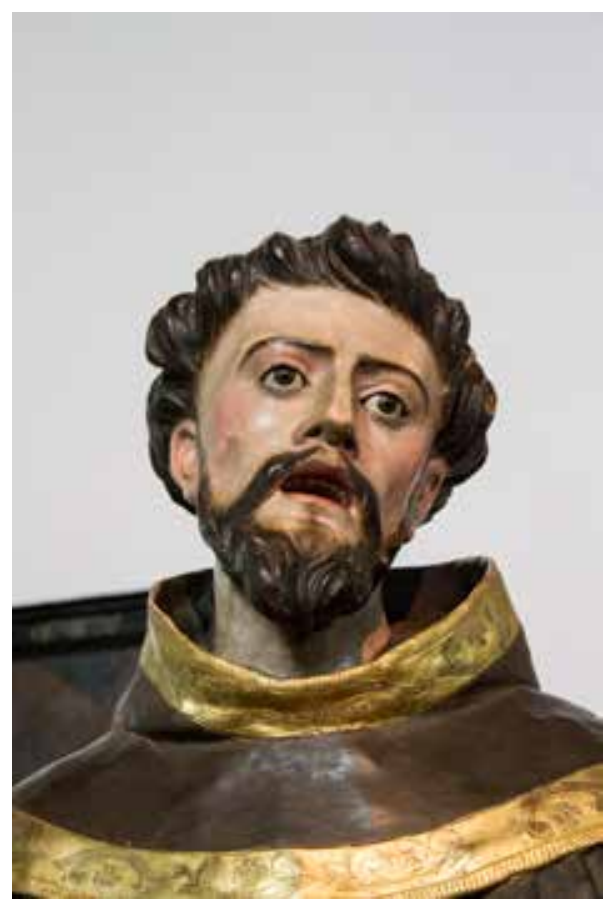

Figura 3. Pedro Roldán (atrib.): San Francisco, 1670-1672, convento de Santa Clara (Zafra). Fotografía del autor.

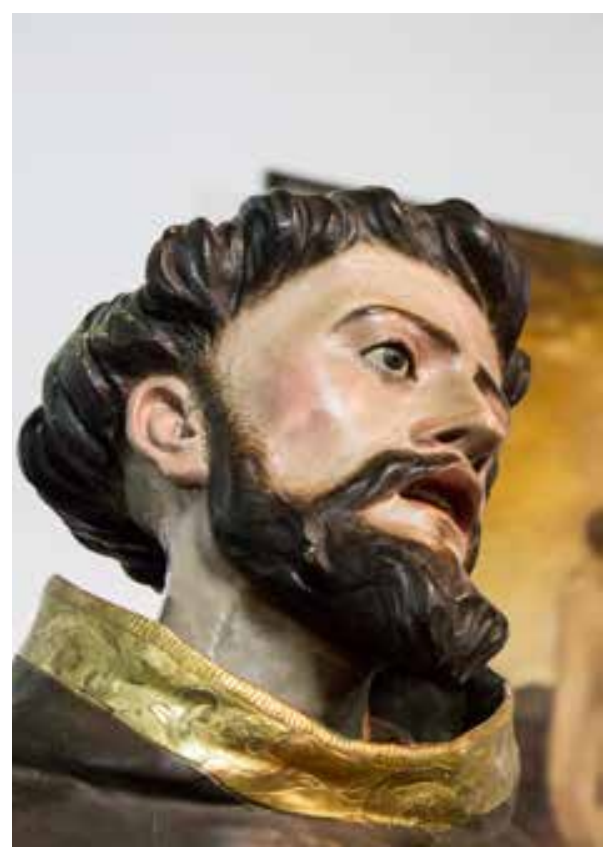




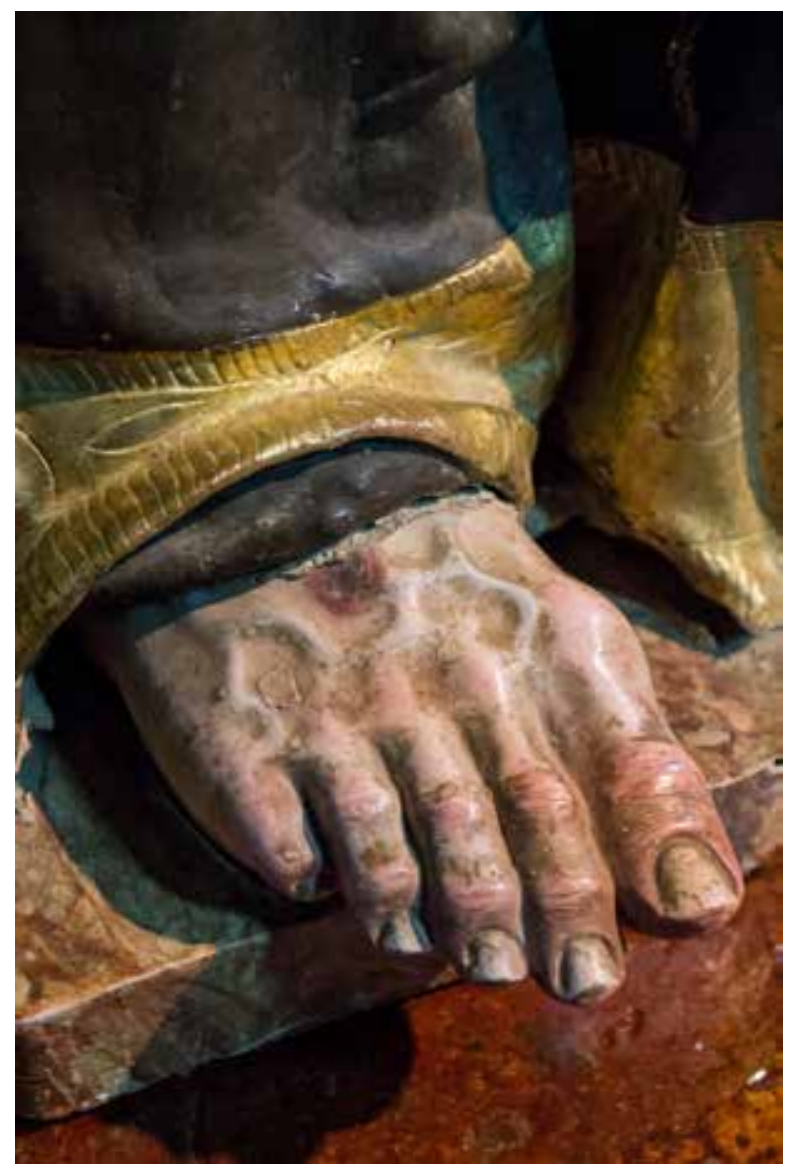

Figura 4. Pedro Roldán (atrib.): San Francisco, 1670-1672, convento de Santa Clara (Zafra). Fotografía del autor. 